\title{
El ojo microscópico: la relevancia de lo nimio y lo mínimo en el arte narrativo, pictórico y guiñol posrevolucionario
}

\author{
A microscopic eye: the relevance of the small and the insignificant in \\ narrative art, pictorical art and postrevolutionary guignol theater \\ O olho microscópico: a relevância do miúdo e o mínimo na \\ arte narrativa, pictórica e Guignol pós-revolucionário
}

\section{Juan M. Berdeja}

UNIVERSIDAD DE GUANAJUATO, MÉXICO

Doctor en Literatura Hispánica por El Colegio de México. Profesor/ investigador invitado en la Universidad de Guanajuato, México.

Entre sus publicaciones más recientes se encuentran: "Una novela indicial: El olvido que seremos de Héctor Abad Faciolince" (CIALCUNAM, 2017); "“نUsted gusta? Vamos a leer». El Señor de Palo (1932) como proyecto literario" (Universidad Autónoma de Querétaro

- Editorial Calygramma, 2018); "Releer", introducción del libro Mirar no es como ver: inéditos y ensayos críticos sobre la obra de Efrén Hernández (Universidad Autónoma de Querétaro - Editorial Calygramma, 2018). Correo electrónico: jberdeja@colmex.mx

\section{Artículo de investigación}

Este artículo es una versión modificada de un texto presentado en un seminario sobre vanguardias artísticas y pedagogía coordinado por Doris Sommer en Harvard University. Asimismo, la presente versión corresponde a un trabajo conjunto con Yanna Hadatty en su seminario de tesis en la Universidad Nacional Autónoma de México, al que fui invitado cuando preparaba mi proyecto de posdoctorado. El proyecto de esta investigación fue presentado en la Universidad de Guanajuato, México (2016), para su ampliación. Cuenta con apoyo del Consejo Nacional de Ciencia y Tecnología como parte del Programa de apoyo para estancias posdoctorales desde agosto de 2017.

Documento accesible en línea desde la siguiente dirección: http://revistas.javeriana.edu.co 


\section{Resumen}

Este artículo muestra ciertos nexos, eslabones perdidos, que conectan al arte mexicano de principios del siglo pasado con la llamada Generación del Medio Siglo. Se estudian probables vínculos desde el fenómeno de la relevancia de lo mínimo, la representación de lo aparentemente baladí y lo trivial. Si hubo, por un lado, descripciones desde lo panorámico, el diálogo como forma dominante, las vastas escenas de gesta revolucionaria y política: la gran novela de la Revolución Mexicana y las representaciones del conflicto armado y los murales, por otro aparecieron imágenes de lo pequeño, lo nimio, lo microscópico: cuentos sobre la grandeza de lo cotidiano, pinturas sobre los espacios más mínimos, un arte de escenas habituales en que la violencia o la generación de una patria no son los temas.

Palabras clave: panorama indicial; vanguardias artísticas mexicanas; narrativa, pintura y teatro guiñol

\section{Abstract}

This article highlights certain lost links which connect the Mexican art of the beginning of the last century with the socalled Generación del Medio Siglo. These probable links are studied from the phenomenon of the relevance of the small and the representation of things apparently trivial. While there were, on the one hand, descriptions using dialog as the dominant form, numerous scenes of revolutionary political conflict, the great novel of the Mexican Revolution and depictions and murals of the armed conflict, in the other hand were images of the small things, the insignificant and the microscopic: stories about the greatness of the day-to-day life, paintings of the most minimal spaces, an art made of everyday scenes where violence and the building of a homeland.

Keywords: Indicial picture; Mexican artistic avant-garde; narrative, painting and guiñol theatre

\section{Resumo}

Este artigo mostra certas ligações, elos perdidos, que conectam a arte mexicana de princípios do século passado com a chamada de Geração do Meio Século. Estudamse prováveis liames desde o fenómeno da relevância do mínimo, a representação do aparentemente banal e o trivial. Se houve, por um lado, descrições desde o panorâmico, o diálogo como forma dominante, as vastas cenas de gesta revolucionária e política: o grande romance da Revolução Mexicana e as representações do conflito armado e os murais, por outro, apareceram imagens do pequeno, o miúdo, o microscópico: contos sobre a grandeza do cotidiano, pinturas sobre os espaços mais mínimos, uma arte de cenas habituais em que a violência ou a geração de uma pátria não são os temas.

Palavras-chave: panorama indicial; vanguardas artísticas mexicanas; narrativa, pintura e teatro Guignol

\section{Cómo citar este artículo:}

Berdeja, Juan M. "El ojo microscópico: la relevancia de lo nimio y lo mínimo en el arte narrativo, pictórico y guiñol posrevolucionario". Cuadernos de Literatura 22.43 (2018): 146-170. https://doi.org/10.11144/Javeriana.cl22-43.omrn 
"Un acto de creación no tiene prisa; nos lee, nos privilegia infinitamente".

\section{Introducción ${ }^{1}$}

Rubén Darío, en su colección de "rescates" bibliográficos firmada en París, que lleva por título Los raros (1905), buscó llevar al público una serie de textos únicos, quizá olvidados, casi siempre ignorados. Fuera de constituir un ajuste de cuentas con los autores que ahí aparecen -acaso una propuesta de canon personal-, tenemos ahí un gesto crítico: ¿qué se escapa de la crítica? ¿Qué libros -imperdibles, según el poeta- merecen salir del olvido por excéntricos, porque hacen saltar la estructura? ¿Cuáles son, si las hay, sus posibles constantes?-.

Propongo recuperar la iniciativa de Darío para revisar la época posrevolucionaria en México. En ese periodo vieron la luz manifestaciones artísticas que, si bien en su tiempo no gozaron de mucha atención, hoy se comunican íntimamente con nuestra sensibilidad. Esta -a mi parecer y con riesgo de reducir un fenómeno que es un cúmulo de subjetividades- se compone de los siguientes rasgos: la desmesurada preocupación del "individuo por sí mismo", el humor absurdo, los juegos de palabras, la crisis espiritual, la crítica política que ya denunciaba las problemáticas sociales en aquella época (y que hoy perviven, hay que decir), las escenas cotidianas que conectan con perspicacia las cuitas diarias con los asuntos filosóficos y religiosos más trascendentes, las historias que enfrentan la no-significación del individuo mostrando su melancolía y su soledad, las representaciones de miembros de una sociedad que gira sobre sí misma y que no busca (quizá porque piensa que no lo necesita) un sentido y menos aún una teleología común.

1 Sea esta nota un agradecimiento a las investigadoras académicas Doris Sommer y Yanna Hadatty por las conversaciones y las sugerencias sobre el tema aquí tratado. Si bien los aciertos los comparto con estas profesoras, los posibles errores que se encuentren aquí son todos míos. Como adelanté, una versión ampliada de este artículo fue propuesta como proyecto de estudios de posdoctorado en la Universidad de Guanajuato en el otoño de 2016. Ahora mismo estoy ampliando ese proyecto e impartiendo un seminario sobre el fenómeno artístico que se analiza en estas páginas. 
Pensando en esa sensibilidad tan inasible, pero sí experimentada, hay libros, autores, textos literarios, textos pictóricos y otras manifestaciones artísticas que por diversas razones no alcanzaron la fama en el periodo comprendido en este estudio; por lo tanto, ha sido casi nula su recepción y su análisis. Sin embargo, nuestros intereses críticos actuales pueden hallar en ellos un grupo de generalidades estéticas rico y novedoso no solo en técnicas, sino en perspectivas, en estilos y temas.

Si bien cada obra comprendida merece tratamiento aparte desde la perspectiva propuesta, el corpus de estudio de este artículo se afirma como una veta de rarezas que nos ayuda a comprender cómo llegó México al estado artístico actual. Hay ciertos nexos, eslabones perdidos, que conectan al arte de principios del siglo pasado con la llamada Generación del Medio Siglo particularmente. Se busca estudiar probables vínculos desde el fenómeno de la relevancia de lo mínimo, lo aparentemente baladí, lo trivial.

Cabe señalar que este estudio no se formuló como una apología o un análisis categórico; más bien se intenta problematizar o complejizar aún más el canon del periodo posrevolucionario mexicano. Se ensaya un análisis sobre constantes que muestran esas obras raras, únicas. De lo raro, de lo inclasificable y de la combinación surge un suceso estético: la relevancia de lo nimio en un momento histórico y estético en que la épica revolucionaria tenía sobre sí los reflectores. A la par de la narrativa de la Revolución y los murales en los edificios de gobierno -ambos movimientos estéticos presentan cuadros enormes de aglomeraciones de personajes y batallas nada pequeñas, que privilegian la acción-, aparecen historias que recargan las tintas en intersticios habituales de un México todavía en gestación: una confesión en la iglesia, una historia de amor en una vecindad del centro de la ciudad, un pintor haciendo dos autorretratos, los problemas de un pequeño burócrata, un político -solo- hablando de pie sobre una silla, entre otros. Todas aventuras baladís. O no: esos acontecimientos simples funcionan para que los autores desarrollen metáforas, digresiones, imágenes o alegorías en las que tienen lugar la crítica, la filosofía, la burla, la tribulación y el placer, siempre en el más cotidiano de los planos. ${ }^{2}$

2 Carlos Monsiváis, en su importante libro La cultura mexicana en el siglo xx, explica: "Ya no realidad cotidiana sino «parque temático», la Revolución mexicana, pronto nada más la Revolución, se afirma en lo cultural gracias a la narrativa, la pintura de gran calidad, el cine y la idea misma de la singularidad de la nación. Se pone de relieve lo popular (por primera vez en la historia de México) y se proclama el culto institucional a la epopeya, que es sinónimo del 
Por un lado, lo panorámico, el diálogo como forma dominante, los grupos sociales, las vastas escenas de gesta revolucionaria y política: la gran novela de la Revolución Mexicana, las representaciones del conflicto armado (argumentos subordinados a la narración de anécdotas, eventos que giran alrededor de episodios bélicos), los murales. Por otro, lo pequeño, lo nimio, lo microscópico: los cuentos sobre la grandeza de lo cotidiano y lo diminuto con la digresión como recurso esencial, un arte pictórico que llama la atención sobre los espacios más reducidos, muñecos de teatro guiñol que representan escenas habituales en que la violencia o la generación de una patria no son de ninguna manera los temas. Manifestaciones artísticas que han pasado casi desapercibidas porque no muestran ni una preocupación por los movimientos sociales del México de la gesta y mucho menos una influencia marcadamente francesa, rasgos que se opusieron durante el periodo vanguardista mexicano. Son otra cosa: productos artísticos que revelan una búsqueda de lo total en lo diminuto y lo pueril. ¿Cuál sería entonces el resultado de observar esa estética del microscopio que acompañó al proyecto cultural de la Revolución? Siempre habrá, en el arte, disidencias. La negativa a incluirse de ciertos artistas (o la negativa del sistema dominante a incluirlos) es una alternativa en cuanto se legitima una "tendencia" o "dominante artística" -antítesis más o menos adecuada para hablar del arte que respondió al proyecto de nación mexicano-. Peter Berger y Thomas Luckmann trabajan con tal negativa que podríamos denominar "tensión creativa":

Ciertos individuos o grupos dentro de nuestra sociedad tal vez podrían sentir la tentación de "emigrar" del universo tradicional o -peligro aún mayor- de cambiar el orden antiguo según el modelo del nuevo. [...] El resultado histórico de cada lucha de dioses lo decidían los que blandían las mejores armas más que los que poseían mejores argumentos. Lo mismo puede decirse, por supuesto, de los conflictos de esta índole que ocurren en el seno de las sociedades (Berger 137-138).

manejo convenenciero del pasado" (Monsiváis 55). Si, por un lado, la Historia corre gracias a la narrativa de la Revolución, por otro, la historia, ese conjunto de relatos comunes, cotidianos, tiene su representación, entre muchos otros, con los autores agrupados en esta investigación. Si quizá una aproximación al corpus revolucionario sería verlo tendencioso, "convenenciero", como dice Monsiváis (apreciación a todas luces discutible o por lo menos matizable), los autores aquí recuperados reaccionarían a lo "epopéyico" por medio de lo ordinario y la trascendencia de este a través del uso de técnicas artísticas sugerentes y muy singulares, como se intenta demostrar en este artículo. 
Terminada la gesta revolucionaria (sin claros resultados), el ojo microscópico podría ser una posible relaboración de la visión de mundo mexicana en la que ya no se canta precisamente a la guerra, sino al relato de lo cotidiano. No importan los grandes nombres, sino los pequeños objetos. Gesto a todas luces vanguardista y, por supuesto, muy ad hoc a nuestra sensibilidad lectora actual.

A este respecto, no se trata, me parece, de postular una nueva categorización en bandos, anunciar o denunciar triunfos o fracasos, sino de mostrar el nudo. Un punto en que las visiones se complementan. Entendamos al México posrevolucionario como un todo híbrido donde el arte responde a necesidades totales (un paneo que se afirmaba a sí mismo sincero e indispensable para formular una identidad, un país), y al tiempo presenta miradas microscópicas, precisas como bisturís, lúdicas algunas, sórdidas otras.

En el nudo mencionado, lo mínimo solicita lugar como bastión epistemológico y como síntoma de una actitud crítica ante el discurso revolucionario. ¿Qué tipo de arte es ese que mira lo cotidiano en sus puntos más diminutos? ¿Qué mundo nos presentan esos autores? ¿Qué discurso está soterrado en esa perspectiva? ¿Para qué dejar de lado la pretensión de atrapar el todo de una nación en pro de cosmos pequeños? Esas son las preguntas que en esta breve cala se busca resolver.

María Dolores Velázquez "Lola Cueto", Efrén Hernández, Antonio Ruiz "El corcito", Nellie Campobello, fueron artistas mexicanos desencantados del mundo y de su tiempo. Quizá por eso las obras aquí analizadas no se leen y menos aún se estudian mucho (salvo la obra de Campobello). Las manifestaciones artísticas que se proponen aquí como corpus de análisis, en diálogo con el epígrafe de este escrito, "nos leen, nos privilegian infinitamente". Aguardan, acaso, que adaptemos el lente para calibrar su relevancia.

\section{Cuatro miradas excéntricas}

Por respeto a la extensión de este artículo ilustro la perspectiva de análisis con cuatro breves ejemplos de esa mirada microscópica. Sin lugar a dudas el tema y los análisis correspondientes al fenómeno estudiado merecen un acercamiento muchísimo más detallado; ojalá las muestras y sus breves revisiones analíticas aquí propuestas sirvan para llamar la atención sobre la cuestión. 


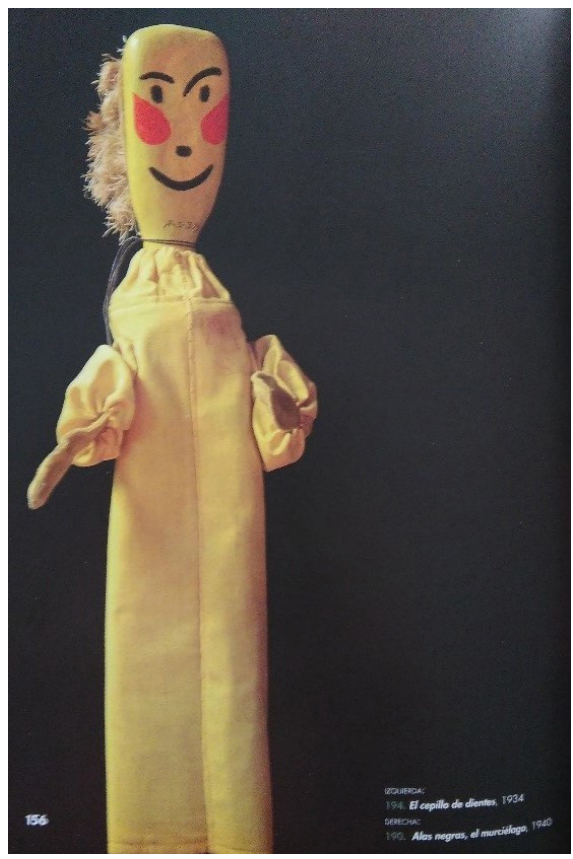

Figura 1. Lola Cueto, El cepillo de dientes, 1934

Fuente: Gaitán Rojo, Carmen y Magdalena Zavala Bonachea. Lola Cueto: trascendencia mágica 1897-1978. México: Instituto Nacional de Bellas Artes, 2009. 156.

María Dolores Velázquez Rivas, "Lola Cueto" (1897-1978), fue pintora, artista de teatro guiñol y se desempeñó como creadora de tapices, bordados y otras artesanías de una altísima calidad estética. El contraste (¿tensión?) entre la pintura académica influenciada por la modernidad y el arte popular mexicano es una marca de época, mas resulta característico que, teniendo el talento y la valoración necesarios para triunfar en la pintura, Velázquez Rivas decida seguir la senda de lo artesanal y las marionetas. La poca crítica que al respecto hay sobre el arte de Lola Cueto reconoce cómo "abraza la copia a expensas de la originalidad" (Flores 70). ${ }^{3}$ Esto quiere decir que Cueto

3 En esta investigación se han encontrado dos textos críticos dedicados a la obra de María Dolores Velázquez en los cuales se hace hincapié en la obsesión por el detalle. Sin duda, el más provechoso es el que coordinaron conjuntamente Carmen Gaitán Rojo y Magdalena Zavala Bonachea: Lola Cueto: trascendencia mágica 1897-1978, donde no solo se aprecia el conjunto de obras de la artista, sino también se recogieron testimonios de familiares y estudios sobre algunos de los trabajos de la autora nacida en la Ciudad de México. Otro volumen en el que se hace una revisión del proyecto artístico de Lola Cueto es "Lola y Germán Cueto: dos rutas al vanguardismo en el México posrevolucionario" de Tatiana 
retomaba imágenes recurrentes en los tapices o los títeres, por ejemplo, y las adaptaba y recreaba en pos de un estilo propio que la lleva a dar fuerza a escenas automatizadas (siguiendo las propuestas de Viktor Shklovski): un viejo cepillo de dientes abandonado (figura 1), un altar de santo, la imagen guadalupana, Jesús en la cruz, los cuentos de Charles Perrault, un niño enfermo, una clase de escuela primaria, etcétera.

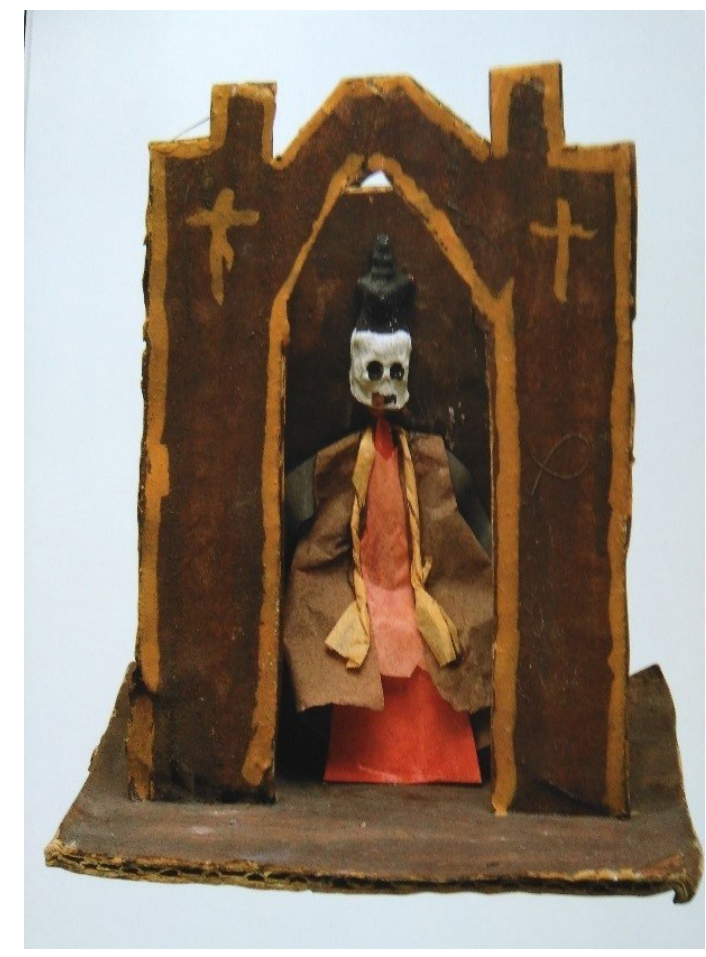

Figura 2. Lola Cueto, Confesión con ángel, 1933-1960

Fuente: Gaitán Rojo, Carmen y Magdalena Zavala Bonachea. Lola Cueto: trascendencia mágica 1897-1978. México: Instituto Nacional de Bellas Artes, 2009. S.p.

Si lo tradicional se basa en la repetición como técnica y como tema, esta artista, como se aprecia en las ilustraciones aquí recuperadas, cuestiona las formas. Usa una máquina de coser para bordar y manualmente trabaja poco, contrario de lo que se esperaría, en el quehacer artesanal. En pequeños cambios, Lola Cueto reformula la tradición tanto en técnica cuanto en temáticas.

Flores, incluido en el volumen coordinado por Dina Comisarenco Mirkin: Codo a codo: parejas de artistas en México, citado en este artículo. 
Muestra de ello es la marioneta Confesión con ángel (1933-1960) (figura 2), donde mínimas variaciones a un tema y un acontecimiento periódico (la confesión católica) denotan intenciones y preocupaciones no solo espirituales, sino satíricas, marcadamente lúdicas. Una maqueta en la que la convención (católica), la crítica a las instituciones, a las prácticas sociales y a la espiritualidad, la semiología y el humor se unen en la "simple" imagen recurrente del sacerdote en el confesionario.

Nótese, por ejemplo, el rostro del confesor: es el de una calavera. Asociada esta imagen siempre a la muerte, también nos recuerda que en el fondo todos somos iguales. ¿Cómo interpretar ese gesto en la obra de Cueto? Quizá la autora trata de disminuir el poder que la Iglesia tenía en la época, recordándonos la condición humana de los sacerdotes. Aquí, el confesor no se vincula con Dios, sino con lo humano y lo terrenal. Cueto desconecta lo invisible (Dios, el plano espiritual, lo sagrado) de lo visible (el sacerdote); lo incorpóreo se vuelve íntimamente material, físico, perecedero.

La artista mexicana nos muestra que esa autoridad que juzga los pecados no es de ninguna forma un nexo deifico, todo lo contrario: es como nosotros, fenece. Si los símbolos de la capilla llaman al referente más poderoso, Cristo, el rostro de la figura del sacerdote hace una contra extraordinaria que muestra la complejidad y variedad de perspectivas que la religión puede tener. Así, podemos decir que Cueto ha esbozado una imagen más "real" - por sofisticada- del sentir religioso de la época.

Para apoyar esa lectura, tenemos el material con que trabajó la artista: el cartón. Un material muy convencional se usa para tratar un tema trascendental: la expiación de los pecados. Cueto sugiere, con ese mínimo gesto, que nada hay de relevante en una confesión. La diada "cartón/perdón espiritual" podría acusar no solo una crítica o una relajación de lo espiritual de alguien que se pronunció con una fuerte conciencia religiosa, sino la búsqueda de lo divino por medio de materiales muy comunes, muy a la mano de cualquier persona. Acaso la propuesta de Cueto sea que lo convencional también puede contener lo trascendental. Con esos mínimos guiños: el rostro del sacerdote, la tapa de cartón que sirve como base a la escultura, las cruces en la maqueta del confesionario, Lola Cueto representa una conciencia religiosa compleja, rica y divagante. En esa pluralidad de significados, su obra brilla con especial fulgor en un México que buscaba (erróneamente) conceptos rotundos antes que visiones múltiples, complicadas.

Por su parte, Efrén Hernández (1904-1958) ha sido siempre visto y antologizado como un escritor excéntrico, una curiosidad. Habría sido clasificado 
por Darío como un "raro" de haber sido más famoso como escritor y menos como el mentor editorial de Juan Rulfo. La crítica no lo estudia suficientemente: demanda demasiado analizar una obra con una lógica a contrapelo, aunque hay críticos que aceptaron la difícil tarea y formularon estudios sobre esta oscura obra: Tatiana Bubnova, Lourdes Franco, Yanna Hadatty, Edith Negrín, Alejandro Toledo, entre otros. ${ }^{4}$

Hernández muestra caras del mundo que no podríamos apreciar sin su literatura: su mirada que tiende hacia lo mínimo muestra los puntos que unen al orbe diegético en elementos diminutos que van cobrando relevancia. Hallamos así en su obra una corcholata abandonada que hace las veces de cobija para una niña, un agujero por donde se filtra una corriente inofensiva de aire que impide que se narre el cuento "más logrado del mundo", una cadenita tirada en un parque condena a un hombre a inmolarse, etcétera; todos son objetos que llevan a los protagonistas a entender que su mundo es el de la correspondencia, donde todo, por más insignificante que parezca, contiene en sí al universo.

"Unos cuantos tomates en una repisita" (Phanal, 1928) es un relato donde se halla la grandeza de lo mínimo y lo nimio en unas bayas y una breve grieta en un muro. Texto por demás sugerente al equiparar el amor con un tomate, a la fisura con el cielo, y donde la Historia nacional es apenas un pretexto para sumergirse en cuestiones filosóficas y evadirse de lo social. Interesante, sin duda, el hecho de mirar hacia otro lado frente al asesinato del presidente Obregón en el restaurante La Bombilla; hecho que tiene lugar como al descuido en el texto. En el cuento leemos que:

4 Tatiana Bubnova, "La paloma, el sótano y la torre de Efrén Hernández y novela de la revolución mexicana" (15-36). De la misma autora: "La poesía de Efrén Hernández: visión autoscópica de la vida y la experiencia espiritual" (83-96). De la autoría de Lourdes Franco Bagnouls, está el "Prólogo", en Efrén Hernández, Bosquejos (8-27). En cada uno de los siguientes libros, Yanna Hadatty Mora dedica un capítulo respectivamente a la cuentística hernandiana: Autofagia y narración. Estrategias de representación en la narrativa iberoamericana de vanguardia (19221935). El otro libro donde la investigadora analiza la narrativa de Hernández es La ciudad paroxista: Prosa mexicana de vanguardia (1921-1932). Asimismo, Edith Negrín Muñoz fue una crítica pionera de la obra en cuestión con su tesis de licenciatura Comentarios a la obra de Efrén Hernández. El trabajo de rescate y divulgación de Alejandro Toledo ha sido de vital importancia. Entre sus aportes figuran la edición de las Obras completas del autor guanajuatense (tomos I y II, 2007 y 2012, respectivamente) y la compilación de estudios y ensayos Dos escritores secretos: ensayos sobre Efrén Hernández y Francisco Tario. 
Mirar no es como ver. Ver, es dejar que la luz obre sobre el dispositivo de los ojos. El que abre los ojos, el que no se los tapa, ése es el que ve. Mirar, en cambio, es entregarse por medio del sentido de los ojos, es polarizar las potencias del ser hacia el objeto que capturan los ojos. Aquel que abre los ojos, y condensa, además, sobre las obras que la luz obra en sus ojos, su presencia, ése es el que mira. (Hernández, Obras completas 210)

En general, el estilo de Hernández muestra cambios vertiginosos, extraordinarios por lo bien que define y combina múltiples registros; el anterior pasaje es una muestra. ¿Podemos extraerlo de su contexto y sigue comunicando una idea, una definición, una deliberación? Sí: va de lo mínimo y lo personal a lo general y totalizador. Su breve digresión es un indicio de la importancia de lo mínimo en un mundo en que se tiende a dar relevancia a lo máximo. Observar con detenimiento, esa es la consigna.

Entonces, ver es no taparse los ojos, un acto sin intención que ocurre - simple y llanamente- gracias a que se tienen ojos. Es lo obvio, lo natural. Mirar es convertirse en el objeto enfocado, "entregarse" nos dice el narrador, convertirse en lo que se ve. El narrador (en tercera persona) explica que hay que "polarizarse" con "el objeto que capturan los ojos": condensar o concentrar la presencia en lo que se ve, eso es mirar según este pasaje; asimilarse con lo que se experimenta por medio de los ojos. El relato mismo nos explica lo que hace Serenín (protagonista del relato) cuando ve y mira, pero Hernández tiene el cuidado de no escribir "Serenín no se tapa los ojos", sino utiliza un abstracto "el": "el que no se tapa los ojos, ése es el que mira", tal es un hecho narrativo mínimo que adquiere relevancia conforme avanzamos en nuestra lectura del cuento y puede trascender hacia nuestra visión de mundo porque discursivamente abstrae la reflexión y la lleva a dos planos: diegético (Serenín) y extradiegético (lector/es).

En "Unos cuantos tomates en una repisita" se recupera, luego, el inicio de la digresión citada en un pasaje descriptivo y se hace una precisión: "Mirar no es como ver. Mirar es entregar el alma al objeto que capturan los ojos. Es algo más que ver, es ver con sed. En el mirar de Serenín [...] se ve esta sed sorber, querer beber algo a este muro, y en su expresión se nota, cierta, esa demanda interna, profunda y fervorosa que muestran los que oran en silencio" (Hernández, Obras completas I 211). Por medio de atribuciones insólitas ("beber algo a este muro") se intensifica el deseo de Serenín, quien mira el muro para encontrar a la china, su amada. El valor estético (con clara dominante metafórica) de esa digresión al relacionar el deseo con el acto de 
ver y con la necesidad imperiosa de algo ("demanda interna") es altamente eficaz en lo semántico, pues explica y transmite con eficiencia la relación entre el acto de mirar y el amor, diada importantísima para la exégesis y que manifiesta una intención ensayística al revisar un proceso de aprehensión del mundo, una suerte de interiorización de este por medio de la mirada.

Este tipo de digresiones -ya breves, ya extensas- no solo atañen a la perspectiva de los personajes o de los diversos narradores, también son disquisiciones, valoraciones, exámenes u opiniones que trascienden el espacio narrativo y explican o problematizan nuestro cosmos, la manera en que actuamos, pensamos o sentimos.

La hibridación entre lo ensayístico y lo narrativo es un rasgo común en la narrativa, pero llama la atención cómo particularmente la prosa hernandiana se "detiene" o se "escurre" (a falta de términos más adecuados) para pensar, definir, charlar, debatir, deliberar con contundencia y profundidad ya en interrupciones breves, ya en fragmentos por demás extensos.

Célebre narradora, cronista, bailarina, coreógrafa y poeta, Nellie Campobello (1900-1986) se lee en tres claves: la historiográfica (testigo revolucionaria), la feminista y la de la visión infantil. Los estudios que sobre ese triángulo de apropiaciones existen son valiosos sin duda, pero quizá un estudio sobre el uso de los diminutivos y sus implicaciones exegéticas, así como esa obsesión por el detalle que sostiene en sus "estampas" de la vida revolucionaria nos dé otra visión de una compleja obra con interpretaciones múltiples. Campobello representa ígneamente lo que Jorge Aguilar Mora identifica como condición sine qua non de la narrativa que establece vínculos con la Historia:

Narrar hechos con Historia o hacer Historia contada no garantiza que se produzca la trabazón indisoluble de narración e Historia. Un elemento indispensable es el gesto auto-conciencia narrativa, no a la manera de comentario teórico sino como parte de la misma trama narrativa. Otro elemento fundamental es la presencia de la Historia no como un dato cronológico (fecha, referencia "objetiva" a algún hecho "histórico"), sino como postura del tiempo que determine la estructura de la narración: la historia como fuerza secreta, la Historia como potencia moduladora de la visión, de los objetos, de los hechos narrados. La Historia como gemela de la Naturaleza (Aguilar Mora 27).

En Cartucho, Relatos de la lucha en el Norte de México (Campobello) tiene lugar una perspectiva indicial que hermana, como propone Aguilar Mora, Naturaleza e Historia. Para ello la escritora norteña usa estrategias narrativo- 
líricas para representar la violencia; esta se manifiesta por medio de procesos desautomatizadores: si bien las batallas narradas por varias novelas como Los de debajo de Mariano Azuela, „Vámonos con Pancho Villa! o Se llevaron el cañón para Bachimba de Rafael F. Muñoz (por poner ejemplos), intentan representar (o mimetizar) los referentes históricos, Campobello, en Cartucho o en Las manos de mamá, va en una dirección artística diferente porque apuesta por el estilo lírico y la óptica aparentemente ordinaria sobre los objetos y los cuerpos inertes que resultan de las batallas: mira los efectos en los cuerpos en su centro más diminuto; asimismo cifra la perspectiva desde una visión aparentemente infantil que singulariza los síntomas de la violencia: la sangre de un fusilado "como cristalitos rojos que ya no se volverían hilos calientes de sangre" (Campobello 117) es un ejemplo.

Otro caso es "El cigarro de Samuel", donde se relata que Samuel Tamayo "le tenía mucha vergüenza a la gente. No lo hacían comer delante de nadie. Cuando hablaba, se ponía encendido, bajaba los ojos y se miraba los pies y las manos. No hablaba" (Campobello 146), pero "pelea como un verdadero soldado" a decir de Francisco Villa, y murió, fiel, junto al cadáver del Centauro del Norte:

Se quedó dormido dentro de un automóvil; Villa y Trillo también se quedaron allí, dormidos para siempre. Cosidos a balazos. Samuel iba en el asiento de atrás, ni siquiera cambió de postura. El rifle entre las piernas, el cigarro en la mano, sólo ladeó la cabeza.

Yo creo que a él le dio mucho gusto morir, ya no volverá a tener vergüenza. No sufrirá más frente a la gente. Abrazó las balas y las retuvo. Así lo hubiera hecho con una novia. El cigarro siguió encendido entre sus dedos vacíos de vida (Campobello 146).

El cigarro funciona como símbolo de la vida y el recuerdo de ese personaje que fallece en la diégesis. Pero, quizá más relevante, muestra al Villa cotidiano que muere para que se cuente la historia de un ordinario cigarro. En Cartucho, Villa, ese personaje protagonista de la historia y de la Historia, se relaciona constantemente, casi con obsesión estilística, con objetos nimios como el mencionado: unas sandías, su voz de plática, un sombrero, una paloma (Campobello 148, 149, 150, 101, respectivamente).

Volviendo sobre el caso de Samuel Tamayo en específico, ocurre que, como indica Kristine Vanden Berghe, "Campobello da al cuerpo muerto una presencia central en buena parte de Cartucho, lo muestra sujeto a las leyes de la decadencia, lo representa sin ninguna forma de horro o de asco y enfrenta 
al lector a un reconocimiento extremo de la corporalidad humana" (Vanden Berghe 54). En el caso específico de "Las tripas del general Sobarzo", nótese el uso del diminutivo para llevar a cabo un juego doble en el que, por un lado, se deja ver la perspectiva infantil y, por otro, se hace una loa lúdica de un síntoma de la violencia: las tripas.

¿Oigan, ¿qué es eso tan bonito que llevan? Desde arriba del callejón podíamos ver que dentro del lavamanos había algo color de rosa bastante bonito. Ellos se sonrieron, bajaron la bandeja y nos mostraron aquello. "Son tripas", dijo el más joven clavando sus ojos sobre nosotras a ver si nos asustábamos; al oír "son tripas", nos pusimos junto de ellos y las vimos; estaban enrolladitas como si no tuvieran punta. “iTripitas qué bonitas!, ¿y de quién son?”, dijimos con la curiosidad en el filo de los ojos (Campobello 117).

Una escena que debería mover al asco de la narradora, se utiliza, antes bien, para mostrar el acostumbramiento (automatización) a la violencia y a los restos humanos; en general, no sucede así con el lector promedio, que se disgusta solo de pensar en las tripas rosas sobre el lavamanos (o se mueve al morbo o recuerda la asimilación infantil de ciertos sucesos).

El relato de donde se extrae la cita anterior ejemplifica el gusto por lo violento de la narradora niña de Cartucho y la búsqueda de la desautomatización de la violencia mediante la exaltación estética y la perspectiva de zoom in basada a su vez en una sinécdoque: las tripas por el general, el general por el orden bélico, el orden bélico por la realidad nacional. Campobello arroja su red en una sola frase. Atrapa así una variedad de puntos de vista. Todos quirúrgicos. El panorama indicial cobra una fuerza extraordinaria con las técnicas de la escritora. Cartucho es un péndulo que va de lo narrativo a lo lírico, por eso trasciende la violencia trivializándola. Se mueve del referente histórico a la aprehensión estética de la lucha y la agresividad. Va y viene en segmentos breves, concisos y profundos. Comunica lo historiográfico con lo artístico y la memoria con lo estético en imágenes que semejan un zoom cinematográfico.

Así, lo mínimo adopta la relevancia de un estallido: truena un cuete que, como ocurre en el México moderno, puede ser el ruido de una bala disparada. El cuete es el instrumento de un juego, una celebración, un pasaje cotidiano; la bala disparada es la herramienta de la violencia, síntoma de la muerte, la intrusión de la Historia en la historia. "Las tripas del general Sobarzo" y el sutil uso del diminutivo nos llevan a una radicalización de lo que Wolfgang Iser denominó "juego serio": "En Cartucho, la Revolución es una época en la que 
los muertos no impiden que se ría o se juegue, más bien lo contrario" (Vanden Berghe 121). El disparo adquiere la dimensión del cuete y no necesariamente se trivializa la muerte, la violencia, la gesta revolucionaria, sino que se enmarca con fruición y se retrata al ser humano desde una de sus más importantes características: el placer de su violencia y la violencia de sus placeres.

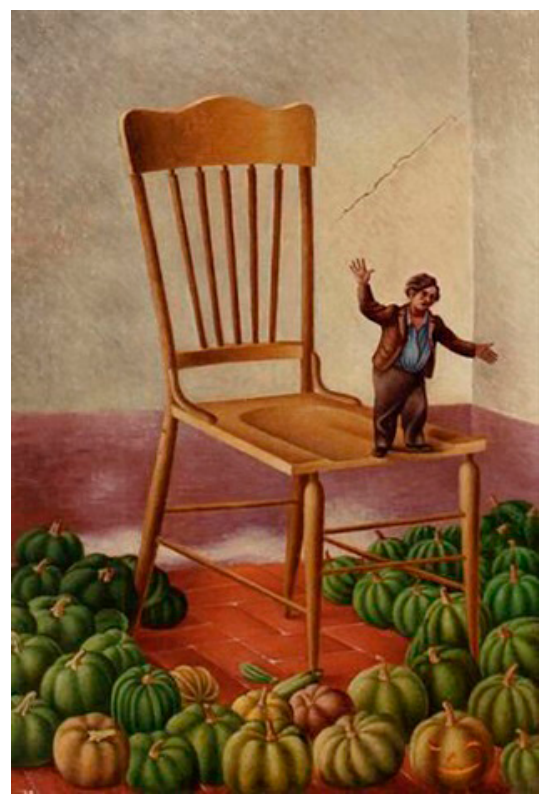

Figura 3. Antonio Ruiz, Líder orador, 1939

Antonio Ruiz (1892-1964): pintor de las escenas más diminutas. El discurso revolucionario oficial se apoyó no solo en una narrativa que, aunque muy crítica, cantó las pretendidas glorias de la lucha armada; la imagen pictórica (asimismo crítica y de denuncia, solo recuérdese el corpus de Azuela) funcionó igual de eficaz para sustentar el nuevo proyecto de nación... Frente a los muralistas de la época, "El corcito", como fue conocido, pintaba sobre timbres postales, representaba escenas microscópicas donde la vida tiene lugar en las coordenadas de lo imperceptible y lo cotidiano, lejos de la violencia bélica. En el fresco Líder orador (1939) (figura 3) se observa cómo en lo microscópico este autor representa un mundo en crisis, donde los tamaños importan, donde la dimensión cobra la magnitud de la crítica social. Se nos muestra a un cabecilla insignificante. Alguien que no tiene voz porque se dirige a unas calabazas, no a sus iguales. La diferencia entre emisor y receptores 
acusa una ruptura del acto comunicativo. La inexistencia del entendimiento. Política y pueblo están disociados y su relación minimizada (visualmente).

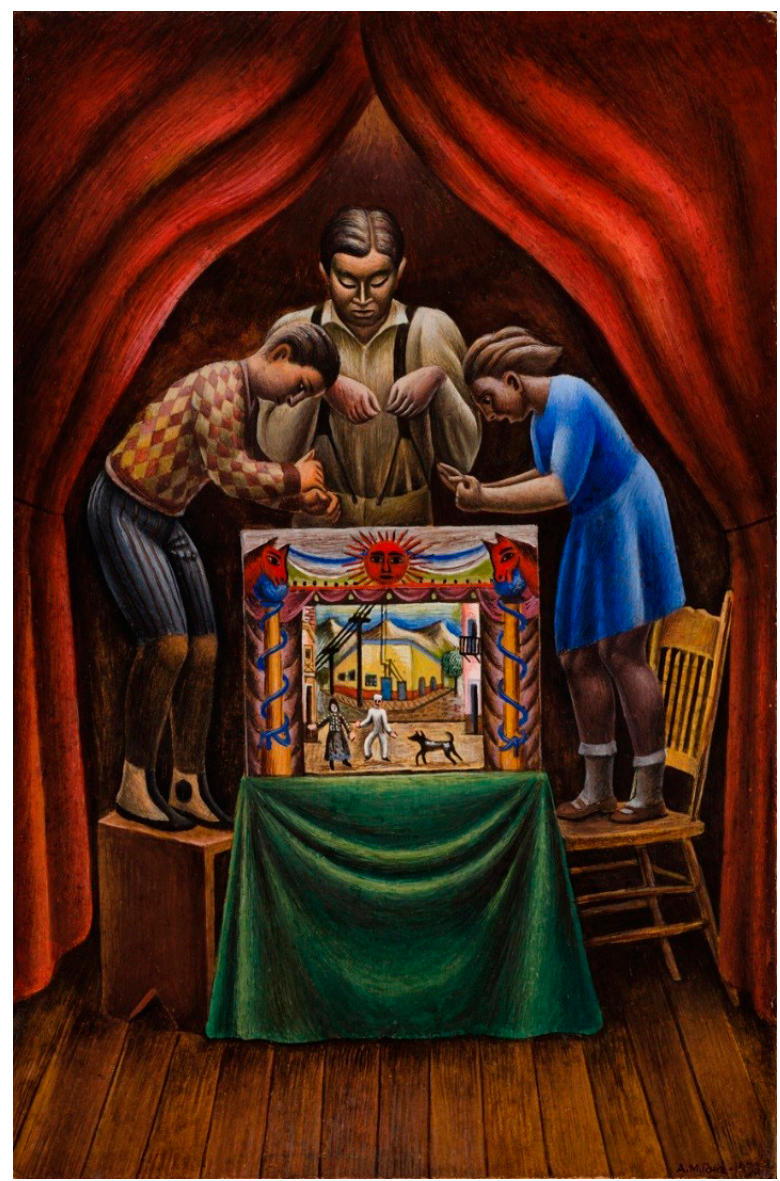

Figura 4. Antonio Ruiz, Títeres, 1933

En la pintura El sueño de la Malinche (1939) vemos un pueblito sobre el cuerpo de una mujer; Rita Eder, en "El sueño de la Malinche y María Magdalena: algunas afinidades", destaca el "carácter alegórico" de esa obra pictórica, rasgo que puede verse también en la construcción de cosmos pequeños al interior de orbes miméticos. En el temple sobre masonite Títeres (1933) (figura 4), Ruiz representa un mundo de marionetas más dinámico y colorido -vivo, diríase- que el de fuera, mismo que intenta imitar el orbe empírico. En contraste con la oscuridad y la insignificancia del primer plano, el ámbito de la representación con los títeres está lleno de detalles, colores, movimiento y luz, mucha más luz que la que hallamos en el contexto superior. ¿Qué nos 
dice esto? Quizá se busca otorgar la relevancia de esa escena cotidiana como algo digno de ficción, de contarse o de representarse.

Así, la interpretación puede ser que Ruiz otorga la importancia a la ficción antes que a la "acción". Representar tiene más brillo que la vida "fuera" de la ficción. Acaso el pintor propone que frente a las diversas cuitas de la vida -infantil y adulta, como lo muestran los personajes del primer plano-, la ficción hace las veces de refugio. Dentro de ella hay más vida que fuera de ella. Crítica mordaz a un mundo que se propuso como algo de lo cual había que estar orgulloso.

Tenemos la necesidad de elaborar un mapa que incluya y, sobre todo, analice la propuesta estética de este pintor que se interesa por el espacio minúsculo y ahí cifra su arte. Los muralistas nos dieron un país, El corcito, por su lado, proporciona un mundo casi imperceptible en el que la fiscalización político-social emprendida por el Dr. Atl se completa, se complejiza, se mira en un menudo espejo de indefinida especificidad. ${ }^{5}$

Con base en lo que se ha esbozado en los párrafos anteriores, se puede entender lo diminuto como un gesto de denuncia ante tiempos de guerra y posguerra. Artistas del malestar, los autores elegidos ajustan cuentas a fondo

Una obra de El corcito para tener en cuenta es la pintura Los paranoicos (1941), donde, según consta el boceto, Ruiz intentó retratar a Xavier Villaurrutia (poeta, narrador, crítico literario, etcétera) declamando junto a Roberto Montenegro (muralista y cineasta) y Salvador Novo (poeta, editor, narrador, periodista, etcétera). La pintura acabada sí muestra a un grupo de hombres y mujeres bien ataviados paseando orgullosos y jubilosos por la ciudad, pero los rasgos, en mi opinión, no coinciden con los de los artistas mencionados en el boceto. Se ignoran las razones de este cambio y las motivaciones (a todas luces críticas) de tan característico título del fresco; quizá la investigación pueda arrojar luz sobre este caso. Los paranoicos se incluyó en la exposición ¿̇Por qué tan chiquito pintaba El Corcito? (Ciudad de México, 15 de agosto al 15 de noviembre de 2009), pero se ignora dónde se hallan ahora esos materiales. Según consta Miguel Ángel Morales en su blog Bitácora: "En su Figuras en el trópico (Océano, 1984), al comentar Los paranoicos, Olivier Debroise identificó a Lupe Marín, Salvador Novo, Roberto Montenegro, Xavier Villaurrutia, Manuel Rodríguez Lozano y Antonieta Rivas Mercado. Poniendo en orden a esos personajes de acuerdo a la pintura, de izquierda a derecha estarían: Antonieta Rivas Mercado, Manuel Rodríguez Lozano, Roberto Montenegro, Xavier Villaurrutia y Guadalupe Marín. Debroise no comenta el por qué llegó a esa conclusión. El personaje de la izquierda no es el pintor homosexual Manuel Rodríguez Lozano, ya [que] era demasiado delgado. También se equivocó al identificar a Antonieta Rivas Mercado, quien se suicidó en febrero de 1931 en París. Quizá la incluyó porque estuvo enamorado de 1928 a 1930 del pintor homosexual Manuel Rodríguez Lozano". Artículo en red. 
y desde el fondo con la esencia de la vida y, al tiempo, con el momento histórico del que fueron parte. Desvían -aparentemente- la mirada de la gesta y la política (verdaderos protagonistas en la estética dominante), formulan una perspectiva nada panorámica y crean universos cotidianos, interesantes por diminutos, pues el mundo se presenta como una serie infinita de orbes mínimos. Ese punto de vista les proporciona vitalidad al complejizar la visión artística del mundo. También manifiesta la búsqueda de nuevos derroteros. En sus obras, el rumbo no lo marca el telescopio, sino el microscopio.

Por mi parte, considero que cuando no se cuenta con la capacidad y la disposición de complejizar un panorama estético, la crítica y la pedagogía corren el peligro de la ceguera. Cada autor estudiado da cuenta de un mexicano que piensa y que sufre porque piensa no solo en el ámbito social, sino en su mundo cotidiano y en lo problemático de este. Asimismo, esos intelectuales representan el goce que significa pensar en mínimo. Juegan. Son paradójicos: en lo más reducido hallan el quid del mundo; formulan un cosmos que en un punto exacto encuentra su fuerza y su complejidad: divierte, pero también asusta y pone en crisis. Quizá por eso no hemos sabido con certeza dónde ubicarlos. Con sus particulares formas de narrar y hacer arte, llaman a repensar la memoria estética mexicana. Ponen en jaque los asideros críticos y en ello radica el posible valor de su análisis. Tal vez habría que poner sobre sus miradas las nuestras. Mirar sobre ojos de gigantes. Y así hacer una cartografía de lo minúsculo.

\section{Para problematizar el ojo microscópico}

¿Hacia dónde trascienden -si así lo hacen- esos casos "raros" o extraordinarios cuya cosmovisión se fija en asuntos pueriles y en objetos casi imperceptibles? Hipotéticamente, hay que decir que muestran una forma de estar en el mundo mucho menos pasiva, receptiva y estacionaria de lo que parece en un primer acercamiento. Evidencian una estética activa, viva y, sobre todo, en constante mutación y renovación.

Acaso los resultados de este estudio muestran un paradigma indiciario que formule un modelo de conocimiento. Este, posiblemente, pudo tener lugar en los productos artísticos aquí propuestos (y en muchos otros más) y tal vez sea aplicable a la memoria artística e incluso al canon mexicano. Es probable que estos creadores prescribieran una invitación a leer con atención los datos únicamente en apariencia insignificantes y así descifrar una realidad esencialmente múltiple. Quizá Campobello, Hernández, Cueto y Ruiz aspiraron a ser primordialmente críticos; por tal razón proponen en sus 
narraciones una estrategia de lectura del entorno, de posición, que tiene sus bases en un acercamiento a la representación de la realidad extremadamente preciso y riguroso.

La tarea de revisar este cúmulo de manifestaciones estéticas no es sencilla. Con todo lo problemático que puede ser, es pertinente notar que el periodo al que se hace referencia, en México, tiene dos constantes intelectuales: la preocupación por el lugar que se ocupa en la historia nacional y la crisis. ${ }^{6}$ Ahí, una complicación más: la búsqueda del sentido en lo mínimo. $\mathrm{Si}$ ya se ha estudiado con rigor a la narrativa mexicana como el centro del conflicto entre lo popular y la normatividad, entre lo provincial y lo urbano, habría que revisar el espacio que se formula entre las grandes visiones y la contemplación de lo que se puede denominar como microcosmos. El gesto de ir hacia adentro no solo del mundo, sino del propio ser humano es una marca de la modernidad. Así lo es también cifrar la cámara narrativa o pictórica en el espacio en apariencia más insignificante para ver el universo. El pormenor como centro del sentido.

"Dios está en los detalles", escribió Aby Warburg. ${ }^{7}$ Pensemos en la mirada en "Unos cuantos tomates en una repisita" de Efrén Hernández, que

6 "Es sabido que modernidad histórica y modernidad estética -y dentro de ella, las denominadas vanguardias históricas- parten de la conciencia de una temporalidad datada, que se asume lineal e irreversible, lo que impide que su rechazo sea la reconstrucción de un pasado ideal, pues éste sería irrepetible; por ello, seguramente, se enfrentan más bien los diferentes imaginarios que coexisten en un solo tiempo, como afirmaciones y negaciones de una modernidad cabal: la emergencia multiforme de lo popular regional frente a la normatividad erudita y emparejadora de lo nacional [proyecto de nación], la vida en la provincia versus la vida en la capital, y aún en la demarcación capitalina, la centralidad económico-social de la ciudad moderna opuesta a los rumbos periféricos de la misma: el centro de comercio y de los paseos, frente a las vecindades y los arrabales" (Hadatty, $L a$ ciudad paroxista 18). Las modernidades histórica y estética, como se puede inferir de la cita anterior, tienen lugar en una época de complejidades, de multiplicidad en la forma de ver y experimentar al mundo. Es un contexto de "diferentes imaginarios que coexisten en un solo tiempo". El panorama indicial que asoma en las obras estudiadas podría ser el síntoma de esa variedad de imaginarios que tienen lugar en la modernidad.

7 Según consignan Cristina Tartás y Rafael Guridi en "Cartografías de la memoria. Aby Warburg y el atlas mnemosyne": "En 1905, Abraham Moritz Warburg (1866-1929), más conocido como Aby Warburg, propone un método de investigación heurística sobre la memoria y las imágenes. Warburg era un historiador del arte alemán de origen judío interesado en la cultura clásica occidental, y más específicamente en la presencia y pervivencia en esta de numerosos elementos arcaicos, cuyas relaciones no siempre se regían por principios de causalidad. Obsesionado perfeccionista, acuña la frase «Dios anida en 
convoca las ideas y las conclusiones más rebuscadas; tomemos en cuenta Líder orador, fresco de Antonio Ruiz, donde se representa a un hombre diminuto declamando en una silla enorme dentro de un cuarto de iguales dimensiones; en la historia en que la muerte violenta de un hombre se expone con la exaltación de sus tripas en la narrativa de Nellie Campobello; o en los mínimos rasgos críticos que transforman un acto común de su época (la confesión en la iglesia) en un hecho metafísico situado en un locus cotidiano (el confesionario) en las marionetas de Lola Cueto. El dios del sentido -pudiéramos aducir siguiendo a Warburg- está, para estos autores, en el detalle. A la par de los frescos de la Revolución Mexicana de Mariano Azuela en Los de abajo (1915) y de las representaciones bélicas y sociales de los murales nacionalistas, hay un panorama indicial que captura una radiografía intelectual y afectiva del mexicano, de los mecanismos de elaboración de su visión de mundo y de sus códigos de comportamiento.

Eso que se puede denominar como una poética del microscopio se ha tomado en cuenta para formular los análisis de este estudio y para trabajar en consonancia con lo que se interpreta como una postura estética. Tal es la razón por la que se adopta el modelo de Erich Auerbach en "La media parda" (modelo que ya usé en mi tesis de doctorado): Virginia Woolf, en To the lighthouse, escribe "never did anybody look so sad". Estas seis palabras -mínima frase sentenciosa, pero al tiempo eficaz para comunicar la melancolía de la protagonista- provocan que el alemán cuestione: "¿Quién es el que habla, en este párrafo?, ¿quién contempla a Mrs. Ramsay y hace la observación de que nunca nadie pareció tan triste, que emite conjeturas tan discretamente dubitativas respecto a la lágrima que -quizá- se forma y resbala en la oscuridad[?]" (Auerbach 500). Y para responder esta cuestión el crítico produce uno de los más lúcidos análisis que se han escrito sobre la relación realidad-literatura.

los detalles» (Der liebe Gott steckt im Detail). [...] Poseedor de un ingente catálogo de imágenes, Warburg idea un procedimiento de exploración y presentación de sistemas de relaciones no evidentes". Esa actitud de la búsqueda de lo máximo (Dios) en los detalles, se puede adivinar también en la narrativa mexicana que aquí se analiza. Es posible también postular sobre estos autores lo que George Steiner opina sobre Walter Benjamin: "Al igual que Aby Warburg sabe que Dios está en los detalles, pero también que la inmensidad de Dios está en los detalles". Hay tanto en Benjamin cuanto en los autores aquí agrupados una capacidad de ver la realidad desde las coordenadas de lo mínimo y desde allí reconocer la vastedad y el abismo que supone comprender que en el espacio más pequeño se halla un conocimiento oculto (Steiner 44). 
La intención es recuperar un elemento generador de análisis: lo mínimo discursivo como clave de lectura. Si Auerbach se pregunta por el emisor de la frase que analiza y sus probables intenciones, quizá con respecto al arte mexicano que nos convoca haya que cuestionarse sobre los efectos de lectura de ese tipo de recursos.

Asimismo, se tomaron en cuenta las ideas de Carlo Ginzburg en "Indicios: Raíces de un paradigma de inferencias indiciales" (1979). A lo largo de ese luminoso ensayo, el historiador explica con base en el método de Giovanni Morelli que "se deben examinar los detalles menos trascendentes", postura que identifico análoga en Cueto, Hernández, Campobello y Ruiz aun si estos artistas mexicanos desconocieron las ideas que Morelli publicó entre 1874 y 1876 .

Este crítico de arte buscaba un método para distinguir una obra pictórica apócrifa de una genuina, por medio de la observación minuciosa de lóbulos de orejas, uñas, halos de santidad, etcétera. Lo minúsculo, según su táctica, era el síntoma de la falsedad o de la originalidad. Ginzburg explica que a finales del siglo xix y principios del xx se desarrolló un "paradigma" de lo mínimo, del dato minucioso y por ende indicial, que tendría a Giovanni Morelli (y su método), Arthur Conan Doyle (con su observador detallista Sherlock Holmes) y Sigmund Freud (con su texto El Moisés de Miguel Ángel de 1914, el "lapsus" y su posterior noción "síntoma") como representantes: "En los tres casos se trata de vestigios, tal vez infinitesimales, que permiten captar una realidad más profunda, de otro modo inaferrable. Vestigios, es decir, con más precisión, síntomas (en el caso de Freud), indicios (en los relatos sobre Sherlock Holmes), rasgos pictóricos (en Morelli)" (Ginzburg 143; el énfasis es mío).

Repito para subrayar: Efrén Hernández, Nellie Campobello, Antonio Ruiz y Lola Cueto interpretan en sus creaciones al mundo desde el dato secundario y marginal, aquel considerado poco revelador, pero que oculta y convoca conocimientos y actos relevantes, por lo menos intelectualmente, en minúsculos indicios. Como pertenecen a distintas esferas del arte: el teatro guiñol, la pintura, la narrativa, obligan a pensar al ojo microscópico como un fenómeno vinculante en lo estético muy semejante a la écfrasis: "Se trata de una modalidad discursiva propia de la literatura, que se basa precisamente en la invocación y la evocación de la visualidad, y como tal se convierte en un laboratorio de experimentación idóneo para comparar los diferentes sistemas de representación, y comprobar hasta qué punto es posible el intercambio entre ellos" (Monegal 18). 
Aquello que se encuentra en el detalle, en el objeto diminuto, poco importante en apariencia o trivial, proporciona "la clave para tener acceso a las más elevadas realizaciones del espíritu humano" (Ginzburg 143) y a la vez, siguiendo la cita de Monegal, es un "laboratorio de experimentación idóneo para comparar los diferentes sistemas de representación" que nos manifiesta el intercambio que hubo en lo estético y que, acaso, provino de la esfera social. Todo ello gracias a diversos artificios que otorgan trascendencia a los intersticios minúsculos. Por diversas vías y técnicas, lo exiguo y lo diminuto, en las obras analizadas en este artículo, van cobrando la importancia de una exclamación crítica. ${ }^{8}$ De esta forma, si se aspira a comprender la postura estética de estos artistas del detalle vanguardista, debemos asumirlos como observadores a la vez que constructores de lo mínimo en cuanto a forma y contenido.

Los productos artísticos que se proponen como corpus de estudio funcionan, a mi parecer, para ver al periodo de la modernidad en México como un lente: cuando los autores se preguntan por el qué del mundo (¿qué es? ¿Qué soy con respecto a él?) y el cómo (¿cómo lo represento? ¿Cómo me relaciono con él?), el propio clima artístico responde desde la más característica forma vanguardista: la multiplicidad de interpretaciones. El panorama

8 Piénsese en las tesis sobre la crítica de Ricardo Piglia en Crítica y ficción (1986). Según Ginzburg esta perspectiva de lo mínimo para interpretar el mundo es muy antigua, prehistórica, pues es la manera en que se rastreaba y cazaba, dado que la persecución de una presa implicaba la búsqueda e interpretación de ciertas huellas, de algunos indicios dados. A decir de Carlos Antonio Aguirre Rojas: "En muchas ocasiones, tanto a partir de sutiles «lecturas indiciarias» de los textos, de las fuentes y los testimonios disponibles, [Ginzburg construye] sus siempre audaces e inteligentes conjeturas históricas de explicación, como también a partir del claro análisis exhaustivo e intensivo de los casos, individuos, obras o fenómenos microhistóricos estudiados. Por ejemplo, cuando Ginzburg retoma a Shklovski, Tolstoi, Marco Aurelio, Vasco de Quiroga o Montaigne, entre otros, para explicarnos una de las precondiciones epistemológicas esenciales de construcción de todo discurso o pensamiento social posible que aspire ser genuina y radicalmente crítico, y que es la necesaria postura o actitud del «extrañamiento» o «desfamiliarización» respecto de la realidad o fenómenos específicos que estamos investigando. Procedimiento epistemológico del «extrañamiento», que nos propone recuperar nuevamente la distancia necesaria para, primero, ser capaces de disolver la banalización, simplificación y deformación de las cosas y las realidades que estudiamos" (Aguirre 17-18). Con el presente estudio se busca hacer una "crítica genuina" que "desautomatice" nuestra memoria literaria con respecto a la representación de la realidad en el periodo estudiado. 
indicial propuesto aquí podría ser resultado de la conciencia de un mundo en constante transformación y, por lo tanto, inasible.

La modernidad literaria es la pregunta por los verdaderos nombres de las cosas, como la pintura es la pregunta por la verdadera imagen; siempre desde la subjetividad: la verdad para uno. Si en no pocos manifiestos hallamos afirmaciones, si los diferentes artistas asumen un tono definitorio antes que de cuestionamiento, la actitud de experimentación que aquí nos interesa acusa otro proceder: el cuestionamiento y la reserva.

En esa reacción ante la complejidad y la libertad del arte, los autores elegidos se decantan por un nuevo mito: el punto mínimo. Un espacio donde se trata de explicar al mundo y que se figura un nuevo locus a explorar. En la modernidad, conquistado el mundo por medio de las expediciones y las máquinas de viaje, dominada la noche por medio de la electricidad, el espacio minúsculo parece ofrecer un misterio por el cual preguntarse, para el cual escribir. El nuevo mito: lo que no se ve, pero se sabe que está ahí. Aquello que no se aprecia a simple vista.

En síntesis, dudar de la realidad y de la posibilidad de asir al mundo por medio de las grandes escenas es un acto de humildad ante el cosmos. La duda espuelea al arte y configura la multiplicidad de perspectivas (y verdades). Un resultado de asumir tal modo de ver es ese enfoque en pro y pos de lo diminuto.

Maestros de una forma precisa de entender su cosmos, estos autores develan espacios fulgentes en los que la realidad se toca con el arte en espacios atómicos. Explican que el arte está en todas partes, que el arte puede ver lo complejo y lo bello en los lugares más insignificantes y que allí se puede decir, se puede pintar, se puede crear. De tal forma sentaron las bases para escritores como Juan José Arreola, Rosario Castellanos, Salvador Elizondo, Carlos Fuentes, Juan Rulfo, etcétera. No destruyen las estructuras socioculturales. Estas se hallan ahí, desafiantes en su representación, pero estos artistas no se quedan quietos a causa del marasmo o la impresión... Ven los puntos en que esas estructuras se unen y se tambalean. Donde la visión panorámica falla y no ve, ellos lo hacen. 


\section{Obras citadas}

Aguilar Mora, Héctor. "Prólogo. Novela sin joroba". Se llevaron el cañón para Bachimba. México: Era, 2016. 9-45. Impreso.

Aguirre Rojas, Carlos Antonio. "La obra de Carlo Ginzburg y su significado dentro de los estudios históricos contemporáneos". Contrahistorias: La otra mirada de Clío 23 (2014): 7-21. Impreso.

Auerbach, Erich. Mimesis: La representación de la realidad en la literatura occidental [1942]. Trad. Ignacio Villanueva y Eugenio Ímaz. México: Fondo de Cultura Económica, 2011. Impreso.

Azuela, Mariano. "El novelista y su ambiente II". Páginas autobiográficas. Prólogo Francisco Monterde. México: Fondo de Cultura Económica, 1974. 169-186. Impreso.

Berger, Peter L. y Thomas Luckmann. La construcción social de la realidad. Buenos Aires: Amorrortu editores, 2012. Impreso.

Bubnova, Tatiana. "La paloma, el Sótano y la Torre de Efrén Hernández y la novela de la Revolución Mexicana". Coloquio de literaturas mexicanas 16, 1997. 15-36. Impreso.

Bubnova, Tatiana. "La poesía de Efrén Hernández: visión autoscópica de la vida y la experiencia espiritual". Acta Poética 35.2 (julio-diciembre de 2014): 83-96. Impreso.

Campobello, Nellie. Cartucho. Relatos de la lucha en el Norte de México (segunda edición). México: e. d. i. a.p. s. a., 2007. Impreso.

Eder, Rita. "El sueño de la Malinche y María Magdalena: algunas afinidades". XXV Coloquio Internacional de Historia del Arte "Francisco de la Maza": La imagen política. Ed. Cuauhtémoc Medina. México: Universidad Nacional Autónoma de México - Instituto de Investigaciones Estéticas, 2006. 93-112. Impreso.

Flores, Tatiana. "Lola y Germán Cueto: dos rutas al vanguardismo en el México posrevolucionario". Codo a codo: parejas de artistas en México. Ed. y Coord. Dina Comisarenco Mirkin. México: Universidad Iberoamericana, 2013. Impreso.

Gaitán Rojo, Carmen y Magdalena Zavala Bonachea. Lola Cueto: trascendencia mágica 1897-1978. México: Instituto Nacional de Bellas Artes, 2009. Impreso.

Ginzburg, Carlo. "Indicios: Raíces de un paradigma de inferencias indiciales". Mitos, emblemas, indicios: Morfología e historia. Barcelona: Gedisa editorial, 1999. 138-175. Impreso.

Hadatty Mora, Yanna. Autofagia y narración. Estrategias de representación en la narrativa iberoamericana de vanguardia (1922-1935). Madrid - Frankfurt: Iberoamericana - Vervuert, 2003. Impreso.

Hadatty Mora, Yanna. La ciudad paroxista: Prosa mexicana de vanguardia (19211932). México: Universidad Nacional Autónoma de México, 2009. Impreso. Hernández, Efrén. Bosquejos. Ed., prólogo y recopilación Lourdes Franco. México: Universidad Nacional Autónoma de México, 1995. Impreso. 
Hernández, Efrén. Obras completas I. Ed. y prólogo Alejandro Toledo.

México: Fondo de Cultura Económica, 2007. Impreso.

Hernández, Efrén. Obras completas II. Ed. y prólogo Alejandro Toledo;

bibliografía Luis Mario Schneider, ampliada por Yanna Hadatty.

México: Fondo de Cultura Económica, 2012. Impreso.

Hernández, Efrén. "Unos cuantos tomates en una repisita". Phanal (1928): 12-25. Impreso.

Herner, Irene. "El Corcito: una mirada clara" Nexos. http:// www.nexos.com.mx/?p=6567. Web.

Monegal, Antonio. "Diálogo y comparación entre las artes". Literatura y pintura. Intro., comp. y bibliografía Antonio Monegal. Madrid: Arco Libros, 2000. Impreso.

Monsiváis, Carlos. Historia mínima de la cultura mexicana en el siglo XX.

Ed. Eugenia Huerta. México: El Colegio de México, 2010. Impreso.

Morales, Miguel Ángel. "Sábado 10 de octubre de 2009: Los paranoicos". Bitácora. http://miguelangelmoralex-bitacora. blogspot.mx/2009/10/los-paranoicos.html. Web.

Negrín Muñoz, Edith. Comentarios a la obra de Efrén Hernández. México:

Universidad Nacional Autónoma de México, 1970. Impreso.

Shklovski, Viktor. "El arte como artificio" [1925]. Teoría de la literatura de los formalistas rusos. Comp. y Ed. Tzvetan Todorov. México: Siglo XXI, 2010. 77-98. Impreso.

Steiner, George. "El arte de la crítica: Entrevista con Ronald A. Sharp". Los logócratas. Trad. María Cóndor. México: Fondo de Cultura Económica - Ediciones Siruela, 2007. Impreso.

Tartás, Cristina y Rafael Guridi. "Cartografías de la memoria. Aby Warburg y el atlas mnemosyne". 2013. http://oa.upm. es/23211/1/INVE_MEM_2013_155825.pdf. Web.

Toledo, Alejandro. Dos escritores secretos: ensayos sobre Efrén Hernández y Francisco Tario. México: Consejo Nacional para la Cultura y las Artes, 2006. Impreso.

Vanden Berghe, Kristine. Homo Ludens en la Revolución: Una lectura de Nellie Campobello. Madrid: Iberoamericana Vervuert - Bonilla Artigas Editores, 2013. Impreso. 